\title{
Commentary: Optimizing cerebral oxygenation in cardiac surgery: Neurocognitive and perioperative outcomes
}

\author{
Hilary P. Grocott, MD, FRCPC, FASE
}

\author{
From the Department of Anesthesiology, Perioperative and Pain Medicine, University of Manitoba, Winnipeg, \\ Manitoba, Canada. \\ Disclosures: Author has nothing to disclose with regard to commercial support. \\ Received for publication March 22, 2019; accepted for publication March 22, 2019; available ahead of print May \\ $18,2019$. \\ Address for reprints: Hilary P. Grocott, MD, FRCPC, FASE, Department of Anesthesiology, University of \\ Manitoba, CR3008 - 369 Tache Ave, Winnipeg, Manitoba, Canada R2H 2A6 (E-mail: hgrocott@sbgh.mb.ca). \\ J Thorac Cardiovasc Surg 2020;159:956-7 \\ $0022-5223 / \$ 36.00$ \\ Copyright (C) 2019 by The American Association for Thoracic Surgery \\ https://doi.org/10.1016/j.jtcvs.2019.03.102
}

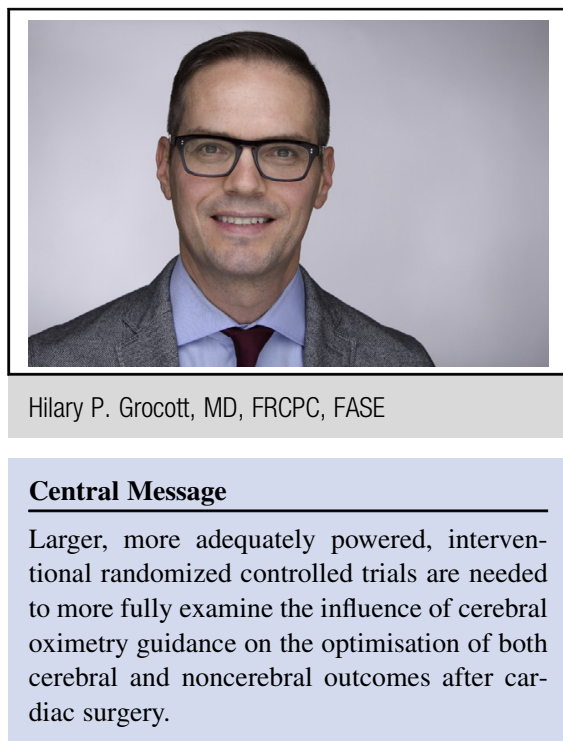

See Article page 943.
Uysal and colleagues ${ }^{1}$ add a small, although no less important, piece of information to the seemingly ever-expanding puzzle surrounding perioperative neurocognitive disorders (PNDs) and the potential factors that may influence them. Their randomized controlled study has a number of strengths, but it also shares some deficiencies that have frequently been seen in similar investigations of cerebral oximetry to optimize cerebral outcome after cardiac surgery. Although the study appears to include a nominal sample size $(n=245)$, the actual number of patients who had both cerebral oximetry monitoring and baseline neurocognitive testing performed was relatively small $(n=59)$, somewhat reducing the confidence one might have in their conclusions. Indeed, discerning the factors that influence the often subtle changes in neurocognitive function that occur in this setting are challenging in small studies. That said, one of this study's notable strengths is that it interrogated for PND at both 3 and 6 month time points after cardiac surgery. These relatively longer-term postoperative PND end points are consistent with the latest nomenclature guidelines that have been promulgated in an attempt to bring better consistency and reliability to studies of PND. ${ }^{2,3}$ Indeed, although recent meta-analyses have suggested a potential relationship between intraoperative management guided by cerebral oximetry and a reduction in cognitive dysfunction, ${ }^{4}$ the frequent variability in defining these cognitive changes (both in terms of cognitive domains that are being measured and the time points at which the assessments are made) brings considerable heterogeneity to the subject.

Despite the cognitive outcome measurements that Uysal and colleagues ${ }^{1}$ report (ie, group mean memory change score) being better at 6 months in the group using cerebral oximetry-guided interventions, the overall presence, duration, and severity of cerebral desaturation

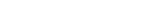


we will not be able to more fully understand the impact of this potentially important monitoring technology on patients undergoing cardiac surgery.

\section{References}

1. Uysal S, Lin HM, Trihn M, Park CH, Reich D. Optimizing cerebral oxygenation in cardiac surgery: neurocognitive and perioperative outcomes. J Thorac Cardiovasc Surg. 2020;159:943-53.e3.
2. Evered L, Silbert B, Knopman DS, Scott DA, DeKosky ST, Rasmussen LS, et al Nomenclature Consensus Working Group. Recommendations for the nomenclature of cognitive change associated with anaesthesia and surgery-2018. Can J Anaesth. 2018;65:1248-57.

3. Grocott HP, Bryson GL. By any other name: consensus in the nomenclature of perioperative neurocognitive disorders. Can J Anaesth. 2018;65:1171-4.

4. Zorrilla-Vaca A, Healy R, Grant MC, Joshi B, Rivera-Lara L, Brown C, et al. Intraoperative cerebral oximetry-based management for optimizing perioperative outcomes: a meta-analysis of randomized controlled trials. Can J Anaesth. 2018;65: $529-42$. 